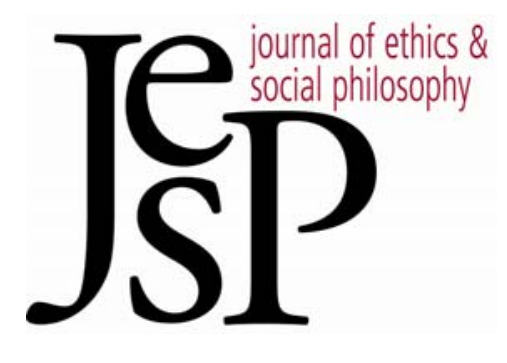

\title{
Answerability without Answers
}

BY GRAHAM HUBBS

Journal of Ethics \& Social PhiLOSOPHY

Vol. 7, No. 3 | August 2013 URL: WWW.JESP.ORG COPYRIGHT (C) GRAHAM HUBBS 2013 


\title{
Answerability without Answers
}

\author{
Graham Hubbs
}

CCORDING TO AN ETHICAL APPROACH that I will refer to
here as rationalist, accounts of moral responsibility are grounded by
explanations of the conditions under which an agent is rationally answerable for her actions and attitudes. In the sense that is relevant here, to answer for an attitude or action is to give reasons that at least purport to justify it, so to hold someone answerable for an attitude or action is to hold her rationally liable for it. If we demand that someone answer for one of her attitudes, that attitude will need to be attributable to her, lest the demand be unintelligible. This much is uncontroversial. What is controversial is whether there are any attributable attitudes for which an agent is morally responsible even though she cannot answer for them. This controversy bears on the classical ethical questions of whether and to what extent morality is a rational enterprise: if there are morally significant attitudes that are attributable to an agent even though she cannot answer for them, then it would seem incomplete, misguided, or worse to treat morality as fundamentally a matter of demanding and giving reasons.

To see what is at stake, let us contrast a behavior that clearly cannot involve either moral responsibility or answerability with one that clearly can. Suppose your new puppy destroys your couch. It makes sense for you to feel anger toward your puppy, to scold it and to train it not to destroy any more furniture, but it makes no sense to demand that it justify what it has done, for a dog is not the kind of being that is capable of justifying its deeds. Contrast this with the case in which I destroy your couch. In many if not most circumstances, it will make sense for you to demand that I justify what I have done; on many if not most moral theories, the answers I can give will be relevant for assessing whether and to what extent I have done wrong. Proponents of the rationalist approach, which include T. M. Scanlon $(1998,2008)$, Angela Smith (2005, 2007, 2008, 2012), and Matthew Talbert (2008, 2012a, $2012 \mathrm{~b}$ ), think that the connection between answerability and responsibility demonstrated in the latter case is relevant for assessing all morally significant behavior. As already indicated, these proponents do not limit the approach's application only to behavior; they also think there are morally significant attitudes, and these also fall within the scope of the approach. All such attitudes, according to the rationalist approach, are proper objects of answerability demands. For example, suppose I have not destroyed your couch, but that I intend to, or suppose that I do not intend to but badly want to. According to the rationalist approach, both my intention and desire are morally significant because both are attitudes I may rightly be called on to answer for, to supply reasons in favor of, to justify.

A related but further reason for calling this approach "rationalist" is the emphasis it places on an agent's evaluative judgments in characterizing that agent's moral responsibility. Smith articulates this connection through a varie- 
ty of metaphors. She claims that it only makes sense to criticize an agent morally "on the basis of things that reflect her evaluative judgments" (2012: 578, my emphasis). In puzzling cases, Smith argues that we should still see an agent's morally significant attitudes as "based on evaluative judgments that the agent, at some level, takes as justificatory" (2012: 581, my emphasis). She also claims these attitudes can be said "to embody evaluative judgments" (2012: 582, n. 11, my emphasis). This diversity of metaphors might make one wonder whether the rationalist believes that the relevant sort of judgment causes the morally significant attitude, or is a constitutive component of that attitude, or is somehow expressed by the attitude. I will explicate this metaphorical language in section 1; at present, I want only to note the centrality of evaluative judgments to the rationalist approach.

One might find the approach attractive, thinking that there are many attitudes whose moral statuses depend, at least in part, on the judgments they are based on, or embody, or reflect, without accepting that all morally significant attitudes have their moral statuses in virtue of appropriately related evaluative judgments. One might take this position if one thinks, as David Shoemaker (2011) does, that there are some morally significant attitudes for which it makes no sense to demand an answer. Like the puppy's behavior, these attitudes are not underwritten by reasons, but unlike its behavior, they nevertheless have moral significance. If there are any such attitudes, then they are not based on or reflective of evaluative judgments in the sense that concerns the rationalist. Shoemaker claims that an agent that holds such an attitude is not answerable for it yet nevertheless is responsible for it. One might argue that some cases of racism involve attitudes of this sort. Imagine a person who holds racist attitudes but knows that they are not evidentially supported. This person believes there are no facts that warrant treating individuals of the relevant race as less worthy of moral respect; if he makes an explicit judgment on the basis of that belief, he will not evaluate members of the relevant race as morally inferior. Nevertheless, he has action-guiding attitudes that lead him to act in insulting ways toward individuals of the relevant race. Because these attitudes are incompatible with the overt judgments the person would make about the matter, it is difficult to see how they embody or reflect his judgments that regard race. If holding these attitudes is morally unacceptable, then the rationalist approach appears too restrictive, for it is not clear what grounds the rationalist has for characterizing such attitudes as having any moral significance.

In this paper, I will argue that these purportedly problematic attitudes pose no threat to the rationalist approach. Shoemaker's discussion of the matter will serve as my argumentative target. ${ }^{1}$ Much of my analysis will focus

${ }^{1}$ I will only be arguing against Shoemaker's attempt to establish what he calls "attributability without answerability"; I shall have nothing direct to say about his critique of Scanlon's view of blame (Shoemaker 2011: 618-27), nor shall I comment on his discussion of psychopathy (627-30). For more on the challenges psychopathy might pose to the rationalist, see Watson 2011; for a rationalist response to these issues, see Talbert (2008 and 2012a). 
on this discussion's central examples. These examples merit careful consideration not just for the challenges they pose; they also serve as useful instruments for clarifying the rationalist's notion of answerability. If I am correct, the rationalist can respond to these examples by describing the agents in them as answerable even though they have no answers for their attitudes. I will elucidate this description by explicating and extending some of G. E. M. Anscombe's remarks on "curious cases" in which her famous question "Why?", in her words, "has and yet has not application; it has application in the sense that it is admitted as an appropriate question; it lacks it in the sense that the answer is that there is no answer" (2000: 26). ${ }^{2}$ While my narrow goal will be to develop these remarks to defend against Shoemaker's specific attack, my broader goal is to equip the rationalist to respond to any view that, like Shoemaker's, divides responsibility into answerability-responsibility and some other sort of responsibility. I offer this discussion, then, in support of what Smith (2012) calls a "unified account" of responsibility. ${ }^{3}$

\section{Attitudes and Answerability}

Let us start by considering the rationalist approach in a bit more detail. One of its goals is to explicate the normative significance we sometimes attach to attitudes that are not the results of decisions and that do not appear to be under one's voluntary control. According to Smith, when we praise or blame someone for holding such an attitude, "it seems we are responding to certain judgments of the person which we take to be implicit in that attitude" (2005: 251). When Smith talks of attitudes "reflecting," "embodying," or being "based on" normatively significant evaluative judgments, she means that we should hold an agent accountable for the attitude as we would if that agent made an explicit judgment with that attitude's content. If we do this, then we treat the attitude as an implicit judgment and thereby conceive of it as within the scope of normative evaluation. Specifically, we treat the attitude as something that can be good or bad depending on the reasons that ground it.

While many who write on the matter are ultimately interested in morality, ${ }^{4}$ these implicit evaluative judgments may be normatively assessable without

${ }^{2}$ For other examples of applying the thoughts in Intention to contemporary philosophical debates, see the essays in Ford, Hornsby, and Stoutland (2011), as well as Hubbs (forthcoming 2013b).

3 This exchange between Shoemaker and the rationalists is not the first whose goal is to elucidate answerability and related notions; a series of papers from Charles Blatz, Ian Harris, and Richard Spanier in the 1970s addresses the same topic (Blatz 1972; Harris and Spanier 1976; Blatz 1976). Along with analyzing the notions of accountability and answerability, these papers discuss the act of demanding that an agent justify herself, the conditions under which that act is justifiable, and whether every such act is itself a sort of blame. I agree with Blatz that not all such acts are blamings (see my remarks at the end of section 2).

${ }^{4}$ Smith praises Shoemaker for highlighting the moral concern of writers, such as herself, whose work is structured by "Scanlonian conceptions of responsibility" (2012: 576). She criticizes others, most notably Neil Levy, for treating rationalists working within the 
being moral. This can be seen in certain cases of arachnophobia, which both Smith and Shoemaker discuss. Suppose an arachnophobe correctly believes that his fear of spiders is unwarranted, yet he still maintains a fearful attitude toward them. In this case, Smith says, the arachnophobe is "open to a particular kind of rational criticism - namely, to a charge of irrationality" (2005: 253). The rationalist treats the arachnophobe's fearful attitude as the implicit judgment that spiders are to be feared, which is not rationally compatible with the relevant evidence. By treating the fearful attitude as something that ought to be determined by the arachnophobe's evidence, the rationalist holds the arachnophobe answerable for the attitude, and the arachnophobe's lack of adequate evidence makes him rationally blameworthy. The rationalist takes moral accountability to be, at base, a matter of this sort of answerability. For example, the racist considered in the introduction is morally accountable for his racist attitude precisely because he is answerable for it, and he is blameworthy because the judgment tacitly expressed by the attitude fails to square with the relevant evidence.

The rationalist's commitment to treating attitudes like the arachnophobe's fear and the racist's aversion as containing tacit judgments follows from her insistence that these attitudes are assessable in terms of reasons. If these attitudes are not understood as containing tacit judgments, it is not clear how their apparent incompatibility with the agent's reasons provides any grounds for criticism. The rationalist must defend this understanding of attitudes, for one might think that the persistence of the arachnophobe's fear, in spite of his knowing its irrationality, shows that the attitude is arational, in which case it is wrong to treat it as containing a tacit judgment liable to rational assessment. Thinking along these lines, Shoemaker says the following of the case: "it seems the connection between [the arachnophobe's] evaluative judgments and [his] attitudes has been severed, for one would expect that [his] judgments about spiders would yield no fear of them" (2011: 607). If there is no such connection, then it seems wrong to hold him answerable for his fear, for it is not a reflection or expression of his evaluations. If the same holds for the racist's aversion, and if that aversion is morally blameworthy,

Scanlonian framework as primarily discussing nonmoral forms of human excellence (cf. 2012: 576, n. 3).

5 It is worth noting here that even if the rationalist "would expect" that one's overt judgments always determine one's attitudes - and it is not obvious that she would - there are all sorts of anti-rationalist positions on which this is not to be expected. One such position, which has generated considerable discussion recently, belongs to Tamar Gendler (2010, chs. 13-14). Gendler would claim that the arachnophobe in this case, even though he believes spiders are not generally to be feared, has an arational, associative, affect-laden, actionguiding, aversive representation of spiders, which she calls an alief about spiders. Gendler would explicitly deny that we ought to expect the agent's aliefs to line up with his judgments, for aliefs and judgments belong to separate parts of the agent's psychology. If my arguments here are correct, then in many of Gendler's examples the agent is answerable for his socalled alief. I say "so-called" here because I think the notion has no explanatory purpose and, as such, is dispensable; on this, see Hubbs (forthcoming 2013a). 
then it likewise seems wrong to hold him answerable for his aversion. Some account other than the rationalist's thus appears necessary to explain its moral status.

One way to answer this complaint is to shift from treating attitudes as being implicit judgments and instead consider them as entailing certain judgments. If the arachnophobe is considered this way, then his rational fault is not that his attitude fails to be determined by the evidence; rather, it is, as Smith herself states in presenting this view, "a direct inconsistency between the judgments [he] explicitly make[s] and the judgments entailed by the attitude [he] in fact hold[s]" (2005: 253). Characterizing the case in terms of this "direct inconsistency" thus depicts the agent as answerable for his phobia. Shoemaker does not think that this solves the rationalist's problem, however. Because the agent is a rational being, he cannot endorse the rational conflict between the attitude-entailed judgment that spiders are generally to be feared and his evidentially based judgment that they are not generally to be feared. The agent's overall condition of irrationality is thus not one for which he can give a justification. "Consequentially," Shoemaker says, "a demand for justification - the answerability demand - to [the agent] for having this condition would be pointless, senseless as a demand" (2011: 608). The same complaint would presumably apply to the example of the racist: he also cannot give a justification for his overall condition of irrationality, so it may seem pointless to demand that he do so. If these demands are senseless, then, Shoemaker thinks, these agents are not answerable for their irrational conditions.

The key move in Shoemaker's argument here is the claim that demanding that the arachnophobe answer for his irrationality is "pointless, senseless as a demand." Shoemaker thinks it is pointless to issue a demand not only for overall psychological conditions of irrationality but also for certain deeply seated emotional commitments. He gives us two examples of such commitments. One is the mother of the serial killer who, in spite of judging her son to be a worthless individual, still finds herself caring for him; the other is the ex-girlfriend who does not believe her abusive ex-boyfriend deserves her care yet goes on caring for him anyway. Shoemaker describes the cares in these two cases as "nonrational" and says that "[w] here one's attitudes are grounded in these sorts of emotional commitments, they float free of the sorts of reasons agents typically take to justify them" (2011: 611, original emphasis). If the attitudes "float free" of justification, then, Shoemaker thinks, there are no grounds for treating them as tacit judgments, so it would be pointless to demand that an agent answer for them as if they were reason-backed judgments.

Shoemaker clarifies what he means by "float free" by articulating this last point in terms of agential capacities. He asserts that "[a] demand for justification presupposes that the agent as he is, is capable of offering a reasonbased account of his actions or attitudes" (2011: 614, n. 30). Note the explicit connection that Shoemaker makes between capabilities and answerability demands: if an agent "as he is" is incapable of giving reasons for his actions 
or attitudes, then it does not make sense to demand that he give reasons - i.e., to hold him rationally responsible - for them. Shoemaker defends this last claim by reflecting on the kind of act that an answerability demand is: "such demands are forms of communication, and as such, they are constrained by the actual capacities of their targets" (ibid.). The capacities in question constrain what may be sensibly demanded of a person: "[y] our demand to me to justify an attitude reflecting a groundless emotional commitment will be without a point as a demand, for I am simply devoid of the resources necessary to engage with your communicative attempt" (2011: 611). According to this line of thought, the mother and the ex-girlfriend lack certain communicative capacities, and it is because of this that they are not answerable for their attitudes.

Shoemaker's critique of the rationalist turns on this last claim. Abstracting away from the details of the cases, the claim is that if a person lacks certain communicative abilities - specifically, the abilities needed to give reasons for attitudes - then there is something wrong with demanding that the person exercise those abilities. One thing wrong with such a demand is that it is pointless. The fact that the demand is pointless, Shoemaker claims, shows that the person is not answerable for the attitudes in question, so it would be wrong to characterize these attitudes as containing tacit judgments. If we are to assess this argument, we will need to know more about the communicative acts of making and responding to answerability demands; in particular, we will need to know what point (or, if there is possibly more than one, points) there can be to making such a demand. Anscombe's discussion of her question "Why?" touches on all of these matters; to aid in our analysis of Shoemaker's argument, then, let us review some of Anscombe's thoughts on "Why?"6

\section{Answering "Why?"}

One standard use of the English word "why" is to request a justification. When it is used to demand a justification for an action, Anscombe claims that the agent of whom it is asked is called on to say "with a view to what" he has performed his action (2000: 63), "what good" he sees in acting as he does (2000: 74). ${ }^{7}$ For example, imagine we are eating breakfast one morning; you do not order bacon, and I ask you why you have made this choice. Suppose you are intensely allergic to bacon and this, you tell me, is why you did not order any. Your answer shows me the good you saw in refusing the ba-

${ }^{6}$ For a summary of "Why?" see Anscombe (2000: 24-26); for a more thorough discussion, see (2000: 9-41).

7 Anscombe's view on this matter has not gone unchallenged; perhaps the most famous recent critique is J. David Velleman's "The Guise of the Good" (2000, ch. 5). I believe that Velleman's arguments succeed only against a mischaracterization of Anscombe's view, but it is beyond the scope of this essay to argue adequately for this claim. Even if Velleman's critique is correct, however, my present use of Anscombe's question "Why?" is unaffected. 
con, for I know that eating things to which one is allergic tends to result in bad consequences. This justifies your choice. Suppose instead that you did not order bacon for religious reasons; suppose you are Muslim, and you tell me this is why you did not order any. In this case, Anscombe says, the good you see in not eating bacon is the good of doing what "suits" the sort of person you are. This also produces a justification. ${ }^{8}$

While any justification will reveal the good the agent sees in his action, not all good-revealing answers to questions involving "why" are justifications. For example, imagine you are having a sneezing fit and I ask you why you keep sneezing. Suppose you respond by saying that sneezing is a mechanism we have evolved to ward off pathogens. This explains the biological benefit that accrues from sneezing, but it is not a justification. A justification does not merely present an action as aiming at some good; it presents an action's aim as determined, at least in part, by the agent's representing the good as a good. When you explain the benefit of sneezing, you do not depict this as aimed at by any representation of yours; you present the "aim" as the product of evolution. By contrast, when one self-consciously refuses bacon in order to avoid the possibility of an allergic reaction, one's representation of eating bacon as harmful (i.e., not good) aims one away from eating it. Similarly, when one refuses bacon in order to follow a Muslim diet, one's representation of bacon as unsuitable for a Muslim diet aims one away from the bacon. For the remainder of this essay, I will follow Anscombe in using "Why?" to refer to questions that concern the evaluative representations that determine an agent's aim. ${ }^{9}$

An agent's honest answer to "Why?" not only reveals what justification, if any, she takes herself to have for the relevant attitude or action, but it may also show whether the demand for a justification is appropriate. The appropriateness of such a demand is partially determined by the action-description that figures in the question; the agent may show it to be inappropriate if she does not know that the action-description applies. This point is demonstrated by Anscombe's example of the man pumping water (2000: 37-49). Suppose a man is pumping water into a house; unbeknownst to him, someone else has poisoned the water. If we come upon the man, we might ask him why he is moving the lever up and down. To this, we can expect a response like, "To pump water into the house." This answer reveals the man's aim, which we may or may not accept as a justification. If we know the water is poisoned,

8 Anscombe discusses suitability in her account of what she calls "desirability characterizations"; on this, see (2000: 70-76).

9 When a person can correctly answer "Why?" she knows her aims in a uniquely firstpersonal way. This self-knowledge is another central topic of Intention (see Anscombe 2000: 13-16 and 49-55) and is arguably the central topic of Moran (2001). Moran's work on selfknowledge has recently been elaborated and extended by a series of essays by Matthew Boyle (2009, 2011a, 2011b). While I do not think that "Why?" can be fully explicated without describing the epistemology of responding to the question, my present purposes do not require that I give this epistemological account. 
we may ask him to say more. Suppose we ask him why he is pumping poison into the house; because he is ignorant, we can expect an answer like, "I did not know the water was poisoned!" While the description "pumping poison into the house" correctly applies to the event, it is not one that the man knows to apply to what he does. Given that he does not know that the description applies to what he does, there are no grounds for asking him to justify the action under that description. This does not mean that no justification may be appropriately demanded of him; depending on the circumstances, it might be appropriate to demand that he justify his ignorance, and failure to meet this demand may provide grounds for holding him responsible for any resulting poisoning. Even if this is so, it is inappropriate to insist that he justify pumping poison, for while he was pumping, he did not know the water was poisoned.

While "Why?" usually applies to a scenario just in case the agent has reasons to give in response to the question, it is possible for an agent to acknowledge that "Why?" applies even though he has no good answer. These are the "curious intermediary" cases mentioned in this paper's introduction, about which, again, Anscombe says that "the question 'Why?' has and yet has not application; it has application in the sense that it is admitted as an appropriate question; it lacks it in the sense that the answer is that there is no answer" (2000: 26). Anscombe groups these cases together with those a person might answer by saying "I just felt like it" or "It was an impulse" - she offers petty theft and doodling as examples. If the petty thief is caught and asked, "Why did you steal that?" his answer, "I do not know" or "I just felt like it" may, by his own standards, fail to provide any justification for the act. These responses nevertheless show that he acknowledges the description "stealing that" to apply to his action. This is to be distinguished from the case in which a person takes what is not hers because she incorrectly believes it to be hers; in such a case, the accused may reject the applicability of "stealing that" by citing her mistaken belief that the thing in question belonged to her. Her case is like that of the ignorant pumper. The petty thief's is of a different sort. When he says of his stealing, "I just felt like it," he admits the appropriateness of "Why?" being asked without purporting to answer the demand. He thereby acknowledges that he is answerable for his theft even though he has no answer to give for it.

These examples show at least two different ends a person may pursue by asking "Why?" 10 One is the end of gathering unknown information. If I think bacon is usually a good thing to order with breakfast and I witness you refusing to order any, your choice may pique my curiosity; to sate it, I can ask you why you have refused to order any bacon. My question is a request for a report: specifically, it is for a report of the good you take there to be in refusing bacon. If you give me an answer that allows me to understand the good

${ }^{10}$ I thank an anonymous referee at the Journal of Ethics and Social Philosophy for inviting me to clarify the different goals one may pursue by asking "Why?" 
you take there to be in your choice, you will have successfully answered my question, and my end of information gathering will thus be achieved. We can also ask "Why?", however, not just to elicit reports but also to demand that an agent do something further should the content of her report fail to meet a rational standard. Smith has this in mind when she characterizes holding an agent answerable as calling on the agent "to acknowledge and to defend or disavow the judgments implicit in her responses to the world around her" (2005: 256, my emphasis). If I am not (merely) curious about your bacon decision but instead (or also) am critical of it, my asking you "Why?" might not (merely) be an investigative inquiry; it might (also) be a demand that you, in some sense, disavow the anti-bacon judgments implied by your act of refusal.

To understand what a call to disavow can amount to in this case, we need to distinguish the various ways in which one may rationally disavow an attitude or action in response to being asked "Why?" "If the attitude is an intention or a desire, then, standardly, to call on a person to disavow the attitude is to call on her to give up that attitude. If I intend or badly want to destroy your couch, then a demand that I disavow my intention or desire is a demand to abandon the intention or desire. A similar point holds for future actions not presently pursued: to demand that a person disavow such an action is to demand that he not initiate it. The term "disavowal" does not apply neatly to ongoing actions, but it should be clear what in this context it would mean to disavow an act one is in the midst of performing: it would be to stop. If I am in the midst of destroying your couch and you call on me to disavow my deed, I will answer your demand only if I quit demolishing the couch. The bacon example might involve a similar form of disavowal: if I manage to convince you that it would be most reasonable to have bacon with breakfast and you in turn order some before our food is served, you disavow the bacon avoidance you had been pursuing by not ordering bacon. In these two cases, an ongoing action (destroying a couch, dining) is altered (by stopping, by changing the order), which thereby alters the action's result (lessthan-total destruction, having bacon with breakfast). If an action is already completed, by contrast, it cannot be given up as an attitude may, nor can it be prevented as a future action may, nor can it be discontinued or altered as a present action may. The petty thief, for example, cannot uncommit his crime. For him, disavowal amounts to forgoing any claim to his action having been legitimate, which, in turn, is to accept that what he has done is wrong. When the thief admits that "Why?" may be appropriately asked of his act of theft, he is accepting the call to disavow the legitimacy of this act if he cannot defend it, which he cannot. He may be incapable of answering the question, but he is not thereby inculpable for his deed.

11 Smith speaks of disavowing the judgments implicit in attitudes or actions, not attitudes or actions themselves, but it is more straightforward to speak simply of disavowing actions or attitudes. 
In the next section, I will argue that attitudes that are recalcitrant to reason, such as phobias and irrational cares, can be subject to this last sort of disavowal demand. Before proceeding to that, however, it may be helpful to close this section by distinguishing between asking "Why?" and blaming. As Scanlon emphasizes (2008, ch. 4), blaming is a form of judgment. To ask "Why?", by contrast, is not to judge, but to question; its force is interrogative, not assertive. To be sure, one may ask "Why?" to establish a basis for blame, and in some cases blame may be implied by asking "Why?" While this may be possible, one may blame without asking "Why?", and one can separate the act of requiring one to disavow an unwarranted attitude or action from the subsequent blame one may issue in response to a failure to disavow.

\section{3. "Why?" and Answerability}

Let us now return to Shoemaker's discussion of the mother and the exgirlfriend, who Shoemaker claims are unanswerable for their irrational cares. If "unanswerable" here means "unable to give a satisfactory answer," then the characterization is apt, for neither has reason to go on caring for her wretched man. If someone sets out to discover the justifications the women have for their cares, that person's investigation will fail, for the would-be justification does not exist. To ask "Why?" to discover these justifications would be pointless. Throughout his discussion, Shoemaker seems to have this sort of information discovery in mind when he speaks of answerability, for he defines the aim of an answerability demand as "a request for the targeted agent to explain herself, to explain what it was about her action that made her think it was worth performing" (2011: 620, my emphasis). The goal of such a request is to discover something unknown.

The case of the petty thief, however, shows that this is not the only thing one can mean by "unanswerable" and that information seeking is not the only possible point of making an answerability demand. The thief can give no reason that justifies performing his petty crime, but he nevertheless may be called on to disavow what he has done, for the relevant question "Why?", as Anscombe puts it, "is admitted as an appropriate question" (2000: 26). As we have seen, the point of demanding that he answer for his deed can be to get him to perform this disavowal - which, again, in this case would amount to accepting that his deed is unjustifiable - and thereby accept responsibility for his action. The petty thief is answerable for his deed, then, where "answerable" means "responsible for defending or disavowing." For Shoemaker's examples to perform the argumentative work he needs of them, it must be wrong to characterize the examples as involving this second sort of answerability. If the mother and the ex-girlfriend are answerable in this way, then their cases are not counterexamples to the rationalist approach.

Comparing the case of the petty thief to those of the mother and the ex-girlfriend, we can frame the issue at hand as a challenge. When we compare the cases, we see that all of them involve at least the apparent ac- 
ceptance of "Why?" as appropriately asked of the relevant action or attitude. We have seen that the petty thief accepts the question, "Why did you steal what you did?" as appropriately asked of his deed. The mother and the exgirlfriend at least appear likewise to accept that "Why?" is appropriately asked of their irrational cares. In each case, the agent knows that she bears the relevant attitude: each is unable to say why she goes on caring for her wretched man, but each knows that she still cares for her man. If either is asked, "Why do you go on caring for him?", neither will reject the description "caring for him" as applying to the case; we may suppose that, in response to the question, each simply says, "I do not know." Saying this provides no answer to the question, but it would appear to acknowledge its applicability. The at least apparent similarity between these cases poses a challenge for anyone wishing to defend Shoemaker's attack on the rationalist approach. The challenge here is to explain why, in spite of this apparent similarity, the mother and the exgirlfriend are not answerable for their cares as the thief is answerable for his deed.

While Shoemaker himself steadfastly avoids talk of "rational control," his defender might find it natural to say that the mother and the ex-girlfriend lack a sort of control over their attitudes that the thief had over his action. ${ }^{12}$ Let us assume that, had the thief believed it to be more reasonable to refrain from stealing than to steal, he would have acted differently than he did; his problem is that he simply did not think much one way or the other about the matter. The mother and the ex-girlfriend differ in this regard. Not only does each believe that her care is insufficiently backed by reason, but each also believes that she has sufficient reason not to care for her wretched man. In spite of this, each goes on caring, which suggests that their cares are recalcitrant to reason. While the thief may have acted differently had he thought more about the reasons for and against stealing what he stole, no amount of thought will bring the mother's or ex-girlfriend's attitudes in line with reason - they are simply incapable of rationally altering their attitudes. Now, in the previous section we said that to disavow an attitude normally is to give it up. If this is correct, then the mother and the ex-girlfriend are incapable of disavowing their cares, at least in the standard way for attitudes; it would seem pointless, then, to demand that they do so. Because they cannot disavow their cares in the standard way, they are not, the defender may conclude, answerable for them. ${ }^{13}$

If we allow, however, that there are other ways in which a person may disavow an attitude, then this description of the women's conditions does

${ }^{12}$ I suspect that Shoemaker does not argue explicitly in terms of control to avoid the line of complaint I will raise at the end of this section against his imagined defender. It is possible that Shoemaker's claims and arguments about answerability are nevertheless driven by these intuitions regarding control, but given Shoemaker's refusal to speak of control, I will claim only that this is a possibility.

${ }^{13}$ I thank an anonymous referee at the Journal of Ethics and Social Philosophy for pushing me to take this argument head-on. 
not demonstrate the failure of the rationalist view. We already considered an alternative when we discussed the petty thief: he cannot undo his deed, but he can admit that it was insufficiently backed by reason. Indeed, this seems like what the women do when they admit that they should not care for their wretched men, yet they go on caring all the same. If they claim that they should not care for the men, they imply that their cares are instances of a sort of attitude about which justifiability demands may appropriately be made; they are not arational, as a sneezing fit is. The women may not be able to disavow their attitudes by eliminating them, but they may still be able to disavow their attitudes by admitting that they are unjustified. Such an admission, moreover, is produced by exercising a communicative ability: they are able to communicate a recognition that justification-demands are rightly asked of their attitudes even though they have no justifications to give. Pointing to these facts, the rationalist may assert that the women do disown their attitudes, that they do have communicative abilities that relate reasons to these attitudes, and so they are answerable for them. That they are incapable of rationally altering these attitudes is irrelevant for this sort of answerability.

Shoemaker's defender might respond here by saying that this characterization, though it clarifies one sense in which the women are answerable, does not depict them as rationally responsible, insisting that they are only rationally responsible if they can bring their attitudes under rational control. Now to take this argumentative tack is to change the terms of the debate, for this response depicts answerability as merely a symptom or outward expression for what really matters, i.e., rational control. To insist that rational responsibility must ultimately be articulated in terms of some sort of control, however, simply begs the question against Scanlon, Smith, and their rationalist allies. As I noted at the outset, a central goal of the rationalist approach is to make sense of the normative significance we sometimes attach to attitudes that appear to be beyond one's voluntary control. Smith explicitly advances her version of rationalism as "an alternative to what [she has] called the volitional view of moral responsibility" (2005: 237). If the defender claims that the rationalists are wrong because, to put it crudely, morality is ultimately a matter of control, she fails to engage with them on their own terms. I suspect that Shoemaker himself is sensitive to this and that, given his desire to address the rationalists on their own terms, this leads him to avoid the use of volitionalist vocabulary. If one eschews the volitionalist idiom, however, it is not clear what grounds one could have for denying that the women in the examples are answerable for their attitudes even though they have no answers to give. If there is no reason besides volitionalism to reject this description, then the cases are not counterexamples to the rationalist approach.

\section{Conclusion}

Shoemaker's own goal is not to repudiate the rationalist approach entirely; rather, it is to challenge the approach to explain cases that he thinks it wrong- 
fully excludes. As we have seen here, his argument turns on his view of the conditions of answerability: specifically, it turns on the claim that one is answerable just in case one has an answer to give. I have argued that the rationalist need not accept this condition. Drawing on Anscombe, the rationalist may insist on the possibility of there being answerability without answers. The rationalist approach to ethics may be liable to other, more general attacks, but it is not undermined by the occasional persistence of attitudes we should but cannot justify. ${ }^{14}$

Graham Hubbs

University of Idaho

Department of Philosophy

hubbs@uidaho.edu

${ }^{14}$ I thank Matthew Chrisman, Jamsheed Siyar, and the referees and editors at the Journal of

Ethics and Social Philosophy for their help developing this essay. 


\section{References}

Anscombe, G. E. M. (2000) Intention, Cambridge, Mass.: Harvard University Press.

Blatz, C. (1976) "A Reply to Harris and Spanier," Journal for the Theory of Social Behaviour 6: 261-66.

(1972) "Accountability and Answerability," Journal for the Theory of Social Behaviour 2: 101-20.

Boyle, M. (2011a) "'Making Up Your Mind' and the Activity of Reason," Philosophers' Imprint 11(17).

(2011b) “Transparent Self-Knowledge," Aristotelian Society Supplementary Volume 85: 223-41.

(2009) “Two Kinds of Self-Knowledge," Philosophy and Phenomenological Research 78: 133-64.

Ford, A., Hornsby, J., and Stoutland, F. (2011) Essays on Anscombe's Intention, Cambridge, Mass.: Harvard University Press.

Gendler, T. (2010) Intuition, Imagination and Philosophic Methodology, New York: Oxford University Press.

Harris, I. and Spanier, R. (1976) "Accountability: Answerability and Liability," Journal for the Theory of Social Behaviour 6: 253-60.

Hubbs, G. (forthcoming 2013a) "Alief and Explanation," Metaphilosophy 44. (forthcoming 2013b) "How Reasons Bear on Intentions," Ethics 124.

Moran, R. (2001) Authority and Estrangement: An Essay on Self-Knowledge, Princeton: Princeton University Press.

Scanlon, T. M. (2008) Moral Dimensions: Permissibility, Meaning, Blame, Cambridge, Mass.: Belknap Press of Harvard University Press.

(1998) What We Owe to Each Other, Cambridge, Mass.: Harvard University Press.

Shoemaker, D. (2011) "Attributability, Answerability and Accountability: Toward a Wider Theory of Moral Responsibility," Ethics 121: 602-32.

Smith, A. (2012) "Attributability, Answerability and Accountability: In Defense of a Unified Account," Ethics 122: 575-89.

(2008) "Control, Responsibility and Moral Assessment," Philosophical Studies 138(3): 367-92.

(2007) "On Being Responsible and Holding Responsible," Journal of Ethics 11: 465-84.

(2005) "Responsibility for Attitudes: Activity and Passivity in Mental Life," Ethics 115: 236-71.

Talbert, M. (2012a) "Accountability, Aliens and Psychopaths: A Reply to Shoemaker," Ethics 122: 562-74.

(2012b) "Moral Competence, Moral Blame and Protest," Journal of Ethics 16: 89-109.

(2008) "Blame and Responsiveness to Moral Reasons: Are Psychopaths Blameworthy?” Pacific Philosophical Quarterly 89: 516-35. 
Velleman, J. D. (2000) The Possibility of Practical Reason, Ann Arbor, MI: Scholarly Publishing Office, University of Michigan Library.

Watson, G. (2011) "The Trouble with Psychopaths," in R. J. Wallace, R. Kumar and S. Freeman, eds., Reasons and Recognition: Essays on the Philosophy of T. M. Scanlon, New York: Oxford University Press, pp. 221-41. 